Correspondence: T. Jindal, Dept of Surgical Disciplines, All India Institute of Medical Sciences, New Delhi 110029, India. E-mail: drtarunjindal@gmail.com

Statement of Interest: None declared.

\section{REFERENCES}

1 Calabrese F, Zuin A, Brambilla E, et al. Pulmonary inflammatory myofibroblastic tumour with unusual octreoscan uptake: two reports. Eur Respir J 2010; 35: 448-450.

\section{From the authors:}

We thank T. Jindal, A. Kumar and R. Kumar for their interest in our previously published article [1]. They also experienced similar PET findings in two cases of pulmonary myofibroblastic tumours $[2,3]$.

Our ${ }^{111}$ In-Diethylene triamine pentaacetic acid (DTPA)-D-Phe1 scans (octreoscan) with relative images were obtained in both cases at 4 and $24 \mathrm{~h}$ post-injection (planar whole-body images and single-photon emission computed tomography, as recommended by the guidelines of the European Association for Nuclear Medicine (EANM) and the Society for Nuclear Medicine (SNM) [4]). The tumour/background ratios were 3.8 and 2.5 , respectively, calculated on the late $(24 \mathrm{~h})$ image.

We thank the authors for mentioning a previous report [5] which describes a pseudotumour with uptake on octreoscan; it seems to be quite interesting, even if in that case the tumour was present in the fossa pterygopalatina, secondary to an unclassified autoimmune disease, while in our two cases the pseudotumours were primary and localised in the lung. Based on octreoscan positivity, somatostatin receptor expression was suggested to be present but it was not demonstrated. This is the reason for our statement in the latter part of the manuscript: "To our knowledge, these are the first documented cases of IMT with positive octreoscan and SSTR immunohistochemistry" [1].

F. Calabrese*, A. Zuin ${ }^{\#}$, E. Brambilla ", P. Zucchetta ${ }^{+}$, F. Lunardi*, M. Valente* and F. Rea ${ }^{\#}$

Depts of *Diagnostic Medical Sciences and Special Therapies, ${ }^{\#}$ Cardio-Thoracic and Vascular Sciences, and, ${ }^{+}$Nuclear
2 Kumar A, Jindal T, Dutta R, et al. Functional imaging in differentiating bronchial masses: an initial experience with a combination of (18)F-FDG PET-CT scan and (68)Ga DOTA-TOC PET-CT scan. Ann Nucl Med 2009; 23: 745-751.

3 Jindal T, Kumar A, Dutta R, et al. Combination of (18)-FDG and (68)Ga-DOTATOC PET-CT to differentiate endobronchial carcinoids and inflammatory myofibroblastic tumors. J Postgrad Med 2009; 55: 272-274.

4 de Ruiter ED, Kwekkeboom DJ, Mooi WJ, et al. Inflammatory pseudotumor of the fossa pterygopalatina: diagnosis and treatment Neth J Med 2000; 56: 17-20.

DOI: $10.1183 / 09031936.00022210$

Medicine, University of Padua Medical School, Padua, Italy. and "Dept of Pathology and Lung Cancer Research Group INSERM U 578, Institut A, Bonniot, CHU Michallon, Grenoble, France.

Correspondence: F. Calabrese, Dept of Diagnostic Medical Sciences and Special Therapies, University of Padua Medical School, Via Gabelli 61, 35121 Padua, Italy. E-mail: fiorella.calabrese@unipd.it

Statement of Interest: None declared.

\section{REFERENCES}

1 Calabrese F, Zuin A, Brambilla E, et al. Pulmonary inflammatory myofibroblastic tumour with unusual octreoscan uptake: two reports. Eur Respir J 2010; 35: 448-450.

2 Jindal T, Kumar A, Dutta R, et al. Combination of (18)-FDG and (68)Ga-DOTATOC PET-CT to differentiate endobronchial carcinoids and inflammatory myofibroblastic tumors. J Postgrad Med 2009; 55: 272-274.

3 Kumar A, Jindal T, Dutta $\mathrm{R}$, et al. Functional imaging in differentiating bronchial masses: an initial experience with a combination of (18)F-FDG PET-CT scan and (68)Ga DOTA-TOC PET-CT scan. Ann Nucl Med 2009; 23: 745-751.

4 Balon HR, Goldsmith SJ, Siegel BA, et al. Procedure guideline for somatostatin receptor scintigraphy with (111)In-pentetreotide. J Nucl Med 2001; 42: 1134-1138.

5 de Ruiter ED, Kwekkeboom DJ, Mooi WJ, et al. Inflammatory pseudotumor of the fossa pterygopalatina: diagnosis and treatment. Neth J Med 2000; 56: 17-20.

\title{
Controlling asthma during pregnancy prevents asthma in children: a Berkson fallacy?
}

\section{To the Editors:}

Assessment of risk factors is absolutely essential to understanding how and why asthma develops in children. We read with great interest the study by MARTEL et al. [1], which was recently published in the European Respiratory Journal, and considered the association between mothers' asthma in pregnancy and their children's risk of developing the disease [1]. 
In that case-control study, children whose mothers experienced moderate-to-severe uncontrolled asthma during pregnancy were at higher risk of being diagnosed with asthma than children whose mothers had mild controlled asthma during pregnancy (adjusted OR 1.27, 95\% CI 1.06-1.52). As the authors found an association between uncontrolled asthma during pregnancy and the development of asthma in children, they concluded that treating pregnant females with asthma would prevent their offspring from developing the disease. This association also led the authors to recommend that asthmatic pregnant females be treated with medication, for the benefit of both mother and child.

The study population was families from Quebec (Canada) that were registered for the provincial prescription drug insurance programme (Régie de l'assurance-maladie du Québec (RAMQ) Médicaments); this is not representative of the general population. To be eligible for the programme, a person needs to meet at least one of the following conditions: 1) be on social welfare; 2) be self-employed; 3 ) be $>65$ yrs of age. $>80 \%$ of those $<65$ yrs of age in the programme receive social welfare. As table 1 in the study by MARTEL et al. [1] shows, most of the mothers in the sample receive social welfare $(87.4 \%$ of cases and $84.8 \%$ of controls). We argue that in that study, poverty acts as a collider of asthma control in mothers and the incidence of asthma in their children. In fact, asthma control is lower in poor than in non-poor females, and the incidence of asthma is higher in children born to poor families than those born to non-poor families. It is well known that medication compliance is lower in poor sectors of society [2] and, more recently, asthma in children has been associated with being a member of a low-income family [3,4]. With these facts, we conclude that the authors may have exhibited Berkson-type bias [5], as the presence of the collider poverty causes a bias that leads to an overestimation of the association between mothers' asthma control and asthma in their children.
Considering that the use of medication in pregnancy is always a delicate issue, further research is needed before it is recommended.

\section{Laprise and M-A. Blanchette}

*Faculté de Médecine, Département de Médecine Sociale et Préventive, Université de Montréal, Montréal, Canada.

Correspondence: C. Laprise, Département de Médecine Sociale et Préventive, Université de Montréal, Montréal, Canada. E-mail: claudie.laprise@umontreal.ca

Support Statement: This work was supported by the Canadian Institutes of Health Research (FRN: 96236) and the Fondation de Recherche Chiropratique du Québec.

Statement of Interest: None declared.

\section{REFERENCES}

1 Martel M-J, Rey É, Beauchesne M-F, et al. Control and severity of asthma during pregnancy are associated with asthma incidence in offspring: two-stage case-control study. Eur Respir J 2009; 34: 579-587.

2 Rona RJ. Asthma and poverty. Thorax 2000; 55: 239-244.

3 Lethbridge LN, Phipps SA. Chronic poverty and childhood asthma in the Maritimes versus the rest of Canada. Can J Public Health 2005; 96: $18-23$.

4 Martel MJ, Rey E, Malo JL, et al. Determinants of the incidence of childhood asthma: a two-stage case-control study. Am J Epidemiol 2009; 169: 195-205.

5 Rothman KJ, Greenland S, Lash TL. Validity in epidemilogic studies. In: Rothman KJ, Greenland S, Lash TL, eds. Modern Epidemiology. 3rd Edn. Philadelphia, Lippincott Williams \& Wilkins, 2008; pp. 128-147. 